\title{
Mental health literacy of school nurses in the United Arab Emirates
}

\author{
Nabeel Al-Yateem ${ }^{1,2,3^{*}}$ (D) Rachel Cathrine Rossiter ${ }^{3}$, Walter Frederick Robb ${ }^{4}$ and Shameran Slewa-Younan ${ }^{5,6}$
}

\begin{abstract}
Background: To support promotion, prevention and early intervention for mental illness school nurses need to be mental health literate.

Methods: Three hundred and thirty-nine school nurses employed in government and private schools from three Emirates in the UAE were surveyed. A culturally adapted Mental Health Literacy questionnaire comprising three vignettes of fictional characters meeting diagnostic criteria for the target conditions along with the Kessler Psychological Distress Scale (K10) was administered to ascertain school nurses' ability to correctly identify the conditions and to elicit beliefs about helpfulness of treatment interventions and of health care providers for these conditions.

Results: Less than $50 \%$ of the respondents correctly identified the disorders presented, while accurate identification of evidence-based interventions was also limited. Correlations between level of psychological distress and level of inaccurate survey responses was also revealed, respondents who correctly identified the correct diagnosis of the vignette and the most appropriate interventions were those who had a significantly lower K10 score.

Conclusions: Low levels of mental health literacy amongst respondents in combination with potential religious and cultural factors as reported in the literature, highlight the need for curriculum enhancements for future health professionals and a targeted program of culturally appropriate professional development focused on mental health promotion for those in clinical practice. The level of psychological distress noted in this cohort also signals a need to ensure that appropriate supports are available for clinical staff employed in schools.
\end{abstract}

Keywords: Early intervention, Health literacy, Mental health, Professional practice gaps, School nursing

\section{Key practitioner message}

What is already known about this topic?

- The World Health Organisation reports mental illness, neurological and substance use disorders as a significant contributor to the global burden of disease and has identified an urgent need to accurately recognise illness and implement proven and cost-effective interventions.

- Mental health literacy assists the recognition, prevention or management of mental illnesses. Increasing research reports both on population wide and specific health care professionals' level of mental health literacy in Western countries. However, there

*Correspondence: nalyateem@sharjah.ac.ae

${ }^{2}$ Research Institute for Medical and Health Sciences (RIMHS), University of Sharjah, Sharjah, United Arab Emirates

Full list of author information is available at the end of the article are no studies in the UAE reporting on either community or healthcare professionals' level of mental health literacy.

- School nurses in the UAE are confronted with significant challenges as an increasing number of children with chronic and complex needs now attend mainstream schools in the UAE. To adequately care for the complex needs of school children, adequate levels of mental health literacy are required.

\section{What's new in this paper?}

- To support promotion, prevention and early intervention for mental illness school nurses need to be mental health literate.

- Results reveal low levels of mental health literacy in school nurses in regard to recognition of and beliefs regarding the treatment of posttraumatic stress dis- 
order, depression with suicidal thoughts and psychosis.

- Religious and cultural factors appeared to further impact on respondents' mental health literacy.

\section{Relevance of this paper to clinical practice}

- These findings highlight the need for curriculum enhancements for future nursing professionals and a targeted program of culturally appropriate professional development focused on mental health promotion for those in clinical practice in the UAE and other countries within the Gulf Cooperation Council (GCC).

- The levels of psychological distress in this cohort signals a need to ensure appropriate supports are available for nursing staff employed in schools, regular clinical supervision is encouraged and peer support is in place to promote early and appropriate help seeking.

- Possible screening of nurses in conjunction with ready access to programs designed to support mental well-being will also serve to develop and support the clinical workforce caring for children and adolescents in the school setting.

\section{Background}

In the rapidly developing country of the United Arab Emirates (UAE), approximately $35 \%$ of the total population are young people (aged $0-24$ years) with close to $21 \%$ aged between 0 and 14 years [Central Intelligence Agency (CIA) 2016]. Similar to other countries comprising the Gulf Cooperation Council (GCC), the focus of health care for the entire population has until recently been primarily on physical health promotion and treatment. Epidemiological data reveals significant progress in decreasing deaths from a majority of communicable diseases and injuries leading to great gains in prolonging life. Consistent with a global trend, the impact of noncommunicable diseases (NCDs) across all sections of the community in the UAE is significant and is estimated to account for $65 \%$ of total deaths in the country [45]. NCDs contribute to increased disability while the prevalence of mental illnesses such as depression and anxiety disorders, especially amongst females has grown rapidly. While UAE specific data is limited, the WHO reports mental illness, neurological and substance use disorders as a significant contributor to the global burden of disease, emphasizing the urgent need to implement proven and cost-effective interventions [36]. In 2010, the Ministry of Health in the UAE identified mental health as amongst the top 5 health priorities in the UAE [22] while in 2015 the neighbouring GCC country of Qatar's Supreme
Council of Health launched a mental health strategy for the years until 2020 [43].

The recent UAE Vision 2021 aspires to achieve prosperity for the citizens of the country with world-class medical care and reduction of health hazards through a growing awareness and prevention programs [32]. The healthcare workforce in the UAE charged with the provision of quality care includes school nurses at both public and private schools in the country. The prescribed scope of practice for school nurses is comprehensive and includes the promotion of health, preventive health care, comprehensive health assessment and referral, mental health protection and intervention and the ongoing management of children with chronic and complex health needs in the school setting [27].

As improvements in health care are achieved an increasing numbers of children with chronic conditions are now attending mainstream schools leading to significant nursing challenges. Further unique cultural and environmental factors contribute to the particular challenges experienced by school nurses in the UAE seeking to meet the needs of the children and adolescents in their care. While infant mortality rates in the UAE are low in comparison with many other Arab countries [1], family units are often large with a significant prevalence of consanguineous marriages (a common practice across the GCC and wider Arab world). This has been found in epidemiological research to account for genetic disorders with high levels of morbidity and mortality such as $\beta$-Thalassemia [18, 39]. Dahdouh et al. [16] draw attention to data suggesting 'a significant association between consanguinity and mental disorders and a higher risk of schizophrenia or bipolar disorders among offspring from consanguineous couples' (p. 104). Environmental factors associated with rapid industrialization and high serum levels of heavy metals have also been linked to learning disabilities in the UAE [46]. Factors such as these constitute additional risk factors for the development of mental health problems particularly among the young.

Children and adolescents living with chronic conditions face ongoing challenges such as repeated hospitalization, ongoing periods of poor health, decreased physical strength and skills or changes in appearance due to illness. These challenges have the potential to impede or delay the achievement of developmental, emotional and social milestones and also represent additional risk factors for the development of mental health problems $[4,9,12,17,31]$. School nurses are well situated to play a vital role in not only helping children and adolescents to manage their chronic conditions but in detecting the early signs of mental distress and disorders in order to intervene promptly and appropriately. 
School nurses in the UAE recently identified the management of students with complex health-care needs as the highest priority area for research along with a number of other priorities including the psychological and behavioral well-being of students [3]. If school nurses in the UAE are to adequately care for the complex needs of school children and support promotion of mental health, prevention of mental illness and early intervention for those developing mental illness, a high level of mental health literacy is required. Mental health literacy was defined by Jorm et al. [28] in 1997 as "knowledge and beliefs about mental disorders which aid their recognition, management or prevention' (p. 182). Increasing attention is being given to researching mental health literacy in western countries, however, Furnham and Hamid [21] highlight the gap in understanding of mental health literacy in non-Western countries. Likewise, research assessing the mental health literacy of health professionals is limited [23, 29, 33]. There are no studies in UAE reporting on the mental health literacy of the general community, specific patient groups or healthcare professionals.

\section{Methods}

\section{Aims}

The primary aim of this exploratory study was to investigate school nurses' level of mental health literacy in relation to posttraumatic stress disorder, depression with suicidal thoughts and psychosis. The secondary aim was to identify participants' capacity for problem identification and their treatment preferences for each problem. A further aim was to obtain a cross-sectional measure of non-specific psychological distress in the target population in order to test for potential associations between psychological distress and mental health literacy.

\section{Design}

The study employed a correlational cross-sectional design and was exploratory in nature as this was the first study of its kind in the UAE.

\section{Participants}

The target population for this study was all school nurses employed in private and government preschools, primary, middle and secondary schools across the UAE. Participants were sought from the accessible population of school nurses in three of the seven Emirates in the UAE (Ajman, Sharjah and Dubai). The current structure of health services responsible for school nurses is complex with administering bodies differing from emirate to emirate. A paper-based survey was distributed to participants by the relevant organisation responsible for the management and oversight of school nurses in each of the three emirates involved in the study. School nurses employed in private schools not under the jurisdiction of emirate wide organisations were accessed via an educational meeting with surveys distributed to attendees. Data collection was undertaken between January and June, 2016. Based on available data and the number of surveys distributed, it is estimated that the response rate was approximately $60 \%$ in the Emirates of Sharjah and Ajman and 35\% in the Emirate of Dubai (the most populous of the seven Emirates in the UAE).

\section{Measures \\ Mental health literacy survey}

The questionnaire was presented in three parts, demographic data (Table 1) followed by three vignettes of fictional characters meeting diagnostic criteria for posttraumatic stress disorder (Fig. 1), depression with suicidal thoughts (Fig. 2) and psychosis (Fig. 3) and concluded with the Kessler Psychological Distress Scale (K10) [30].

Attitudes and beliefs concerning the nature and treatment of Posttraumatic stress disorder, depression with suicidal thoughts and psychosis were examined using a modified version of the mental health literacy questionnaire developed by Jorm and colleagues [28] and SlewaYounan and colleagues [40]. Permission was sought from Jorm and Slewa-Younan to utilize and adapt the mental health literacy questionnaire. Given the exploratory nature of this research, this widely-used survey focusing on the recognition of mental illness in adults was employed as a means to investigate base-line attitude and beliefs about the three conditions in question.

Three case vignette were presented of fictional characters, the first (Miriam) suffering from posttraumatic stress disorder, the second (Abdul) experiencing depression with suicidal thoughts and the third (Saed) displaying symptoms indicative of psychosis. Each vignette was followed by a series of questions addressing the nature and treatment of the problem described, including problem recognition and beliefs about the likely helpfulness of various possible treatments and treatment providers.

Following the presentation of each vignette, participants were asked: 'What would you say is Miriam's/ Abdul's/Saed's main problem'? Participants were required to choose only one answer from a number of options that were listed in random order. For the PTSD vignette the options were 'Fear'; 'No real problem, just a phase'; 'Depression'; 'Weak character'; 'Nervous breakdown'; 'Post Traumatic Stress Disorder'; 'Serious medical condition (e.g. brain tumour); 'Stress'; 'Not integrating well in the UAE/homesickness'; 'Physical condition (e.g. migraine or back pain)'. For the depression with suicidal thoughts vignette the options were 'Fear'; 'No real problem, just a phase'; 'Depression'; 'Weak character'; 
Table 1 Demographics characteristics of participants

\begin{tabular}{|c|c|c|c|}
\hline $\begin{array}{l}\text { Demographic } \\
\text { variables }\end{array}$ & Levels & n (339) & $\%$ \\
\hline \multirow[t]{3}{*}{ Gender } & Female & 292 & 86.1 \\
\hline & Male & 38 & 11.2 \\
\hline & Missing & 9 & 2.7 \\
\hline \multirow{6}{*}{ Age categories } & $20-29$ & 97 & 28.6 \\
\hline & $30-39$ & 142 & 41.9 \\
\hline & $40-49$ & 64 & 18.9 \\
\hline & $50-59$ & 14 & 4.1 \\
\hline & $60+$ & 5 & 1.5 \\
\hline & Missing & 17 & 5.0 \\
\hline \multirow{5}{*}{$\begin{array}{l}\text { Region of } \\
\text { origin }\end{array}$} & North Africa & 18 & 5.3 \\
\hline & Indian sub-continent & 94 & 27.7 \\
\hline & Middle East & 47 & 13.9 \\
\hline & Philippines & 4 & 1.2 \\
\hline & Missing & 176 & 51.9 \\
\hline \multirow{6}{*}{$\begin{array}{l}\text { Years of } \\
\text { residency in } \\
\text { UAE }\end{array}$} & 9 or less & 82 & 24.2 \\
\hline & 10-19 & 41 & 12.1 \\
\hline & $20-29$ & 14 & 4.1 \\
\hline & $30-39$ & 19 & 5.6 \\
\hline & $40+$ & 6 & 1.8 \\
\hline & Missing & 177 & 52.2 \\
\hline \multirow{5}{*}{$\begin{array}{l}\text { Language } \\
\text { spoken at } \\
\text { home }\end{array}$} & Arabic & 68 & 20.1 \\
\hline & English & 28 & 8.3 \\
\hline & Indian (e.g. Hindi, Bengali, Urdu...) & 66 & 19.5 \\
\hline & Filipino & 4 & 1.2 \\
\hline & Missing & 173 & 51.0 \\
\hline \multirow[t]{2}{*}{ Profession } & Medicine & 6 & 1.8 \\
\hline & Nursing & 333 & 98.2 \\
\hline \multirow[t]{5}{*}{ Qualification } & Diploma of nursing & 114 & 33.6 \\
\hline & Bacc. degree, nursing & 43 & 12.7 \\
\hline & Post-grad. cert. nursing & 4 & 1.2 \\
\hline & Bacc. degree in medicine & 2 & 0.06 \\
\hline & Missing & 176 & 51.9 \\
\hline \multirow{6}{*}{$\begin{array}{l}\text { Years of nurs- } \\
\text { ing experi- } \\
\text { ence }\end{array}$} & $0-<5$ & 82 & 24.2 \\
\hline & $5-<10$ & 69 & 20.4 \\
\hline & $10-<15$ & 82 & 24.2 \\
\hline & $15-<20$ & 36 & 10.6 \\
\hline & $20+$ & 48 & 14.2 \\
\hline & Missing & 22 & 6.5 \\
\hline \multirow{7}{*}{$\begin{array}{l}\text { Years of } \\
\text { pediatric } \\
\text { experience }\end{array}$} & $0-<1$ & 26 & 7.7 \\
\hline & $1-<5$ & 91 & 26.8 \\
\hline & $5-<10$ & 39 & 11.5 \\
\hline & $10-<15$ & 26 & 7.7 \\
\hline & $15-<20$ & 6 & 1.8 \\
\hline & $20+$ & 13 & 3.8 \\
\hline & Missing & 138 & 40.7 \\
\hline K10 scores & Mean & SD & 11.7 \\
\hline
\end{tabular}

Table 1 continued

\begin{tabular}{llll}
\hline $\begin{array}{l}\text { Demographic } \\
\text { variables }\end{array}$ & Levels & n (339) & \% \\
\hline K10 ranges/ & Low & 105 & 32.3 \\
distress level & Moderate & 78 & 24.0 \\
& High & 44 & 13.5 \\
& Very high & 98 & 30.2 \\
\hline
\end{tabular}

'Nervous breakdown'; 'Serious medical condition (e.g. brain tumour); 'Stress'; 'Physical condition (e.g. migraine or back pain)'; 'Depression with suicidal thoughts'. For the psychosis vignette the options were 'Physical condition (e.g. migraine or back pain)'; 'Using forbidden drugs'; 'Stress'; 'Serious medical condition (e.g. brain tumour); 'Psychosis'; 'Nervous breakdown'; 'Weak character'; 'Depression'; 'No real problem, just a phase'; 'Anxiety'.

Participant's beliefs about helpfulness of various interventions for the problem described in each vignette were also assessed (Tables 2, 3 and 4). Specifically, participants were asked whether each of a number of interventions within each of three categories-treatments activities, medicine type and people, would be helpful, harmful or neither (helpful nor harmful) for the person described in the vignette. Additionally, participants were asked which one intervention within each category they believed would be most helpful for this person.

While the questionnaire was administered in English, the Australian developed vignettes were further adapted in consultation with academic colleagues to ensure each was culturally acceptable and valid for the UAE context. The format of each vignette was checked carefully to ensure that formal (i.e. DSM-V) diagnostic criteria for PTSD, depression with suicidal thoughts and psychosis were addressed. Care was also taken to avoid technical or medical jargon. The questionnaire was then piloted with ten final year Bachelor of Health Science (Nursing) students for cultural acceptability. Students represented the same cross-cultural backgrounds and languages spoken by the target population (i.e. Arabic, Indian, Philippine, etc.). No changes were required.

General psychological distress To assess the general symptoms of anxiety and depression, the Kessler Psychological Distress Scale (K10) [30] was used. The $\mathrm{K} 10$ is a self-report questionnaire of depression and general mental disorder. Scores range from 10 to 50, with established thresholds of low to mild (10-21), moderate (22-29) and severe distress $(\geq 30)$ applied to provide a measure of symptoms among the partici- 
Miriam is a 37 year old married woman with 3 children, a daughter aged 7, and two sons, aged 5 and 3. Miriam has been living in Sharjah for the past year where she works to provide an income and education for her family. She has attended her local doctor on several occasions with the primary complaint of an inability to sleep. The problem with her sleep started just before she arrived in Sharjah. Prior to leaving her homeland, Miriam witnessed much bloodshed, the complete destruction of her home and the killing of her eldest child. Miriam often felt intense fear for her life and overwhelming helplessness. Her husband is still in their homeland looking after his parents. She reports constant nightmares in which images of death and killing disturb her sleep. She avoids talking about what she has seen and watching news channels in case she see more about homes being destroyed and people being murdered. She is easily startled when she hears loud sounds such as a car backfiring or fireworks. She has very little interest in things around her, including her children's lives and feels little affection towards them. Finally, when questioned on how she views her future and plans for her life, Miriam replies that she does not have a future and doesn't believe she will live a long life.

Fig. 1 Miriam—PTSD scenario

Abdul is 30 years old. He has been feeling unusually sad and miserable for the last few weeks. Even though he is tired all the time, he has trouble sleeping nearly every night. Abdul doesn't feel like eating and has lost weight. He can't keep his mind on his work and puts off making decisions. Even day-to-day tasks seem too much for him. This has come to the attention of his boss, who has threatened to terminate him. Abdul feels he will never be happy again and believes his family would be better off without him. Abdul has been so desperate, he has been thinking of ways to end his life.

Fig. 2 Abdul—depression scenario

Saed is 24 years old and lives at home with his parents. He has had a few temporary jobs since finishing school but is now unemployed. Over the last six months he has stopped seeing his friends and has begun locking himself in his bedroom and refusing to eat with the family or to have a bath. His parents also hearing him walking about his bedroom at night while they are in bed. Even though they know he is alone, they have heard him shouting and arguing as if someone else is there. When they try to encourage him to do more things, he whispers that he won't leave home because he is being spied upon by the neighbour. They realize he is not taking drugs because he never sees anyone or goes anywhere.

Fig. 3 Saed-psychosis scenario

pants [8]. The K10 has good psychometric properties with internal consistency of Cronbach's alpha of 0.86 reported for Arabic speaking populations [42]. It has been widely utilised in internal mental health surveys [30]. Cronbach's alpha in the current study was 0.963 .

\section{Statistical analysis}

Statistical analysis was applied to test the effect of sociodemographic characteristics and the levels of the K10 on responses regarding problem recognition and beliefs about interventions. The tests were based on the research hypotheses and were determined prior to looking at the data.

For categorical socio-demographic variables (sex, years of residence in UAE, language groups and region of origin), the Chi square test of independence $(\mathrm{p}<0.05)$ was applied to the hypothesis that responses regarding problem recognition and beliefs about interventions were independent of the socio-demographic variables.

For numerical socio-demographic variables (age, years of experience and years of paediatric experience) and 
Table 2 Perceived helpfulness of interventions for PTSD vignette 'Miriam' $(n=110)$

\begin{tabular}{|c|c|c|c|c|}
\hline Treatments and activities & Helpful (\%) & Harmful (\%) & Neither (\%) & Most helpful ${ }^{\mathrm{a}}(\%)$ \\
\hline \multicolumn{5}{|l|}{ Treatment } \\
\hline $\begin{array}{l}\text { Psychotherapy focusing on changing thoughts and behaviors (cognitive behavior } \\
\text { therapy) }\end{array}$ & 63.8 & 1.9 & 34.3 & 34.0 \\
\hline Psychotherapy focusing on causes that stem from the past & 55.3 & 8.7 & 35.9 & 17.0 \\
\hline Reading the Koran or Bible & 85.2 & 3.7 & 11.1 & 15.0 \\
\hline Just talking about the problem (e.g. to a family member or close friend) & 62.0 & 9.3 & 28.7 & 8.0 \\
\hline Getting out and about more/finding some new hobbies & 71.8 & 1.0 & 27.2 & 7.0 \\
\hline Getting information about the problem and available services & 84.3 & 5.6 & 10.2 & 4.0 \\
\hline Improving diet and/or getting more exercise & 54.2 & 2.8 & 43.0 & 3.0 \\
\hline Trying to deal with the problem on her own & 31.1 & 32.1 & 36.8 & 3.0 \\
\hline Admission to a psychiatric hospital & 26.0 & 24.0 & 50.0 & 3.0 \\
\hline Relaxation (e.g. having a massage) & 72.6 & 1.9 & 25.5 & 2.0 \\
\hline Psychotherapy focusing on relationships with others & 64.8 & 1.9 & 33.3 & 2.0 \\
\hline Hypnosis & 26.7 & 8.9 & 64.4 & 2.0 \\
\hline Have a prayer session or reading with a religious leader & 61.0 & 1.0 & 38.1 & 0.0 \\
\hline Reading a self-help book & 54.7 & 1.9 & 43.4 & 0.0 \\
\hline $\begin{array}{l}\text { Traditional therapies (e.g. herbs, honey, black cumin seed, olive oil, dates, cupping - } \\
\text { Hijama) }\end{array}$ & 15.7 & 4.6 & 79.6 & 0.0 \\
\hline Drinking alcohol to relax & 2.8 & 77.4 & 19.8 & 0.0 \\
\hline \multicolumn{5}{|l|}{ Medicine type } \\
\hline Anti-depressant medication (e.g. prozac) & 56.4 & 10.9 & 32.7 & 53.1 \\
\hline Medication to help you relax (e.g. xanax, valium) & 57.7 & 8.7 & 33.7 & 38.8 \\
\hline Vitamins and minerals (e.g. vitamin C) & 51.5 & 3.0 & 45.5 & 8.2 \\
\hline \multicolumn{5}{|l|}{ Person/service } \\
\hline Psychologist & 83.0 & 0.0 & 17.0 & 29.9 \\
\hline Psychiatrist & 75.5 & 2.9 & 21.6 & 29.9 \\
\hline Family member & 80.8 & 1.9 & 17.3 & 16.5 \\
\hline Close female friend & 63.1 & 1.0 & 35.9 & 7.2 \\
\hline Religious person or priest & 67.3 & 2.0 & 30.6 & 5.2 \\
\hline Community mental health worker/team (e.g. social worker, mental health nurse) & 66.0 & 3.9 & 30.1 & 4.1 \\
\hline Homeland social group/club & 55.0 & 8.0 & 37.0 & 3.1 \\
\hline Family or local doctor & 65.7 & 3.9 & 30.4 & 2.1 \\
\hline Telephone counselling & 28.7 & 4.0 & 67.3 & 1.0 \\
\hline Close male friend & 11.9 & 19.8 & 68.3 & 1.0 \\
\hline Community religious organization & 36.0 & 5.0 & 59.0 & 0.0 \\
\hline
\end{tabular}

a Percentage of sample rating the specific intervention item as 'the most helpful' for treating problem described in vignette (only one choice per category for each participant)

for the K10 score, the Kruskal-Wallis test $(\mathrm{p}<0.05)$ was used to test the hypothesis that the variable was not significantly associated with responses regarding problem recognition and beliefs about interventions, because a normal distribution could not be assumed, particularly where numbers of responses for problem recognition and beliefs about interventions categories were small. Pairwise post hoc comparisons of significant socio-demographic characteristics were performed using Dunn's procedure with a Bonferroni correction for multiple comparisons, to determine which response categories had significantly different values. Statistical analysis was carried out using $\mathrm{R}$ statistical analysis program version 3.2.2.

\section{Missing values}

Missing values for demographic variables are shown in Table 1 . In the calculation of K10 scores, if there were one or two of the ten items within the score missing, they were estimated as the average of the eight or nine available data points. Records with more than two missing received an overall K10 score of "missing". In the 
Table 3 Perceived helpfulness of interventions for depression with suicidal thoughts vignette 'Abdul' $(n=146)$

\begin{tabular}{|c|c|c|c|c|}
\hline Treatments and activities & Helpful (\%) & Harmful (\%) & Neither (\%) & Most helpful ${ }^{\mathrm{a}}(\%)$ \\
\hline \multicolumn{5}{|l|}{ Treatment } \\
\hline $\begin{array}{l}\text { Psychotherapy focusing on changing thoughts and behaviors (cognitive behavior } \\
\text { therapy) }\end{array}$ & 77.5 & 2.8 & 19.7 & 38.6 \\
\hline Getting information about the problem and available services & 84.4 & 5.0 & 10.6 & 13.6 \\
\hline Psychotherapy focusing on causes that stem from the past & 71.4 & 4.5 & 24.1 & 12.9 \\
\hline Reading the Koran or Bible & 70.9 & 2.1 & 27.0 & 8.3 \\
\hline Admission to a psychiatric hospital & 38.4 & 14.5 & 47.1 & 7.6 \\
\hline Just talking about the problem (e.g. to a family member or close friend) & 68.3 & 4.2 & 27.5 & 5.3 \\
\hline Psychotherapy focusing on relationships with others & 60.0 & 2.9 & 37.1 & 4.5 \\
\hline Relaxation (e.g. having a massage) & 58.3 & 2.9 & 38.8 & 2.3 \\
\hline Improving diet and/or getting more exercise & 62.7 & 2.8 & 34.5 & 1.5 \\
\hline Trying to deal with the problem on her own & 25.0 & 25.7 & 49.3 & 1.5 \\
\hline $\begin{array}{l}\text { Traditional therapies (e.g. herbs, honey, black cumin seed, olive oil, dates, cupping- } \\
\text { Hijama) }\end{array}$ & 24.6 & 11.3 & 64.1 & 1.5 \\
\hline Getting out and about more/finding some new hobbies & 69.6 & 2.2 & 28.3 & 0.8 \\
\hline Have a prayer session or reading with a religious leader & 48.2 & 3.6 & 48.2 & 0.8 \\
\hline Reading a self-help book & 46.7 & 5.2 & 48.1 & 0.8 \\
\hline Hypnosis & 19.0 & 14.3 & 66.7 & 0.0 \\
\hline Drinking alcohol to relax & 7.1 & 76.6 & 16.3 & 0.0 \\
\hline \multicolumn{5}{|l|}{ Medicine type } \\
\hline Anti-depressant medication (e.g. prozac) & 80.3 & 8.5 & 11.3 & 73.7 \\
\hline Vitamins and minerals (e.g. vitamin C) & 53.6 & 5.1 & 41.3 & 13.5 \\
\hline Medication to help you relax (e.g. xanax, valium) & 51.7 & 10.5 & 37.8 & 12.8 \\
\hline \multicolumn{5}{|l|}{ Person/service } \\
\hline Psychiatrist & 79.6 & 4.2 & 16.2 & 43.3 \\
\hline Psychologist & 78.7 & 1.4 & 19.9 & 22.4 \\
\hline Religious person or priest & 67.8 & 2.8 & 29.4 & 8.2 \\
\hline Family member & 71.0 & 0.0 & 29.0 & 7.5 \\
\hline Community mental health worker/team (e.g. social worker, mental health nurse) & 71.1 & 3.5 & 25.4 & 6.0 \\
\hline Family or local doctor & 58.9 & 2.1 & 39.0 & 3.7 \\
\hline Homeland social group/club & 63.6 & 4.2 & 32.2 & 3.0 \\
\hline Close male friend & 50.4 & 2.1 & 47.5 & 3.0 \\
\hline Community religious organization & 42.9 & 0.7 & 56.4 & 1.5 \\
\hline Close female friend & 35.4 & 4.9 & 59.7 & 1.5 \\
\hline Telephone counselling & 32.6 & 7.1 & 60.3 & 0.0 \\
\hline
\end{tabular}

a Percentage of sample rating the specific intervention item as 'the most helpful' for treating problem described in vignette (only one choice per category for each participant)

analyses, cases with missing values were automatically excluded.

\section{Results}

\section{Respondent characteristics}

A total of 324 school nurses and four medical officers participated in this study with all but three completing the Kessler 10 (K10), 54 answered three vignettes, two answered two vignettes and 170 answered one vignette. While the medical officers are included in the descriptive analysis, comparisons between the nursing and medical cohorts was not undertaken due to the small sample size (see Table 1). Of note, although the participants were all employed in the school setting, many respondents did not provide information regarding the level of nursing qualification completed. For those that did respond the majority of participants had undertaken a Diploma of nursing, with a smaller percentage reporting completion of a Bachelor's level qualification in nursing. Only two participants had undertaken postgraduate qualifications in nursing. According to published guidelines for the cut-off scores for the K10 [8], 
Table 4 Perceived helpfulness of interventions for psychosis vignette 'Saed' $(n=83)$

\begin{tabular}{|c|c|c|c|c|}
\hline Treatments and activities & Helpful & Harmful & Neither & Most helpful ${ }^{a}$ \\
\hline Psychotherapy focusing on changing thoughts and behaviors (cognitive behavior therapy) & 82.3 & 1.3 & 16.5 & 41.4 \\
\hline Admission to a psychiatric hospital & 46.6 & 9.6 & 43.8 & 17.1 \\
\hline Getting information about the problem and available services & 78.8 & 5.0 & 16.3 & 8.6 \\
\hline Psychotherapy focusing on causes that stem from the past & 73.4 & 2.5 & 24.1 & 7.1 \\
\hline Reading the Koran or Bible & 72.2 & 2.5 & 25.3 & 5.7 \\
\hline Relaxation (e.g. having a massage) & 48.7 & 1.3 & 50.0 & 4.3 \\
\hline Psychotherapy focusing on relationships with others & 72.5 & 3.8 & 23.8 & 2.9 \\
\hline Just talking about the problem (e.g. to a family member or close friend) & 62.5 & 11.3 & 26.3 & 2.9 \\
\hline Have a prayer session or reading with a religious leader & 51.9 & 2.5 & 45.6 & 2.9 \\
\hline Hypnosis & 28.9 & 10.5 & 60.5 & 2.9 \\
\hline Getting out and about more/finding some new hobbies & 61.3 & 2.5 & 36.3 & 1.4 \\
\hline Reading a self-help book & 42.9 & 9.1 & 48.1 & 1.4 \\
\hline Trying to deal with the problem on her own & 25.3 & 25.3 & 49.4 & 1.4 \\
\hline Improving diet and/or getting more exercise & 40.0 & 2.5 & 57.5 & 0.0 \\
\hline Traditional therapies (e.g. herbs, honey, black cumin seed, olive oil, dates, cupping—Hijama) & 20.3 & 10.1 & 69.6 & 0.0 \\
\hline Drinking alcohol to relax & 3.8 & 77.2 & 19.0 & 0.0 \\
\hline \multicolumn{5}{|l|}{ Medicine type } \\
\hline Anti-psychotic medication (e.g. seroquel) & 64.0 & 6.7 & 29.3 & 41.9 \\
\hline Anti-depressant medication (e.g. prozac) & 57.9 & 7.9 & 34.2 & 35.5 \\
\hline Medication to help you relax (e.g. xanax, valium) & 51.9 & 7.6 & 40.5 & 16.1 \\
\hline Vitamins and minerals (e.g. vitamin C) & 43.6 & 5.1 & 51.3 & 6.5 \\
\hline \multicolumn{5}{|l|}{ Person/service } \\
\hline Psychiatrist & 77.8 & 7.4 & 14.8 & 46.6 \\
\hline Psychologist & 74.1 & 4.9 & 21.0 & 27.4 \\
\hline Community mental health worker/team (e.g. social worker, mental health nurse) & 60.8 & 7.6 & 31.6 & 5.5 \\
\hline Close male friend & 49.4 & 7.6 & 43.0 & 5.5 \\
\hline Family member & 60.8 & 3.8 & 35.4 & 4.1 \\
\hline Religious person or priest & 47.5 & 5.0 & 47.5 & 2.7 \\
\hline Family or local doctor & 41.3 & 6.3 & 52.5 & 2.7 \\
\hline Community religious organization & 34.6 & 6.4 & 59.0 & 2.7 \\
\hline Close female friend & 30.4 & 6.3 & 63.3 & 1.4 \\
\hline Telephone counselling & 22.8 & 8.9 & 68.4 & 1.4 \\
\hline Homeland social group/club & 46.1 & 6.6 & 47.4 & 0.0 \\
\hline
\end{tabular}

${ }^{a}$ Percentage of sample rating the specific intervention item as 'the most helpful' for treating problem described in vignette (only one choice per category for each participant)

almost $44 \%$ of all participants had high or very high psychological distress; $24 \%$ had moderate distress, and 32\% low to mild distress.

\section{Posttraumatic stress disorder clinical vignette 'Miriam' Problem recognition}

In response to the question 'What would you say is Mariam's main problem?' 43 respondents (39.1\%) chose PTSD, and a further 33 (30.0\%) chose "Depression". An additional 23 respondents (20.9\%) thought the character was suffering from "Fear" and collectively, these three responses accounted for $90.0 \%$ of all responses.

\section{Treatment preferences}

Table 2 shows the percentage of respondents who considered each intervention within each subcategory (treatment activities, medicines or people) as 'helpful', 'harmful' or 'neither' for the problem described and which intervention they considered would be the most helpful. The single most helpful treatment activity selected by $34 \%$ of participants was 'psychotherapy focusing on changing thoughts and behavior (cognitive behavioral therapy). 'Reading the Koran or Bible' was the treatment activity most often considered helpful (85.2\%) followed by 'getting information about the problem and 
available resources' (84.3\%) and 'relaxation' (72.6\%). The treatments most often reported as harmful were 'drinking alcohol to relax' (77.4\% of respondents), trying to deal with the problem on her own (32.1\%) and 'admission to a psychiatric hospital' (24.0\%).

With respect to medication, 'anti-depressant medication' was seen to be the most helpful medication (53.1\%) while 'relaxation medication' was most commonly noted as helpful by over half the sample (57.7\%).

In terms of assistance from people, 'psychologists' and 'psychiatrists' were equally selected as the most important individuals to provide help (29.9\%). The participants most frequently cited a 'psychologist' as being helpful (83\%), followed by a 'family member' $(80.8 \%)$ and 'psychiatrist' (75.5\%).

\section{Factors affecting responses to PTSD vignette questions}

Respondents who correctly identified the PTSD vignette as describing a person with PTSD had a significantly lower K10 score $(p=0.018)$. Similarly, respondents with a lower K10 score were more likely to select a 'psychologist' $(\mathrm{p}=0.014)$ whereas younger respondents were more likely to select a 'family member' as helpful treatment providers for Miriam $(\mathrm{p}=0.01)$. Finally, respondents with a lower K10 score were more likely to select an 'antidepressant' as helpful for Miriam $(\mathrm{p}=0.036)$.

\section{Depression with suicidal thoughts clinical vignette 'Abdul' Problem recognition}

In response to the question 'What would you say is Abdul's main problem?' 72 respondents (49.3\%) chose 'depression with suicidal thoughts', and a further 51 (34.9\%) chose 'depression'. An additional 8 respondents (5.5\%) thought the character was suffering from "Stress" and collectively, these three responses accounted for $89.7 \%$ of all responses.

\section{Treatment preferences}

Table 3 shows the percentage of respondents who considered interventions within each subcategory (treatment activities, medicines or people) as 'helpful', 'harmful' or 'neither' for the Abdul's problem and which intervention they considered would be the 'most helpful. 'Getting information about the problem and available services' was the treatment activity most often considered helpful (84.4\%) followed by 'psychotherapy focusing on changing thoughts and behavior (cognitive behavioral therapy)' (77.5\%) and 'psychotherapy focusing on causes that stem from the past' (71.4\%) The single most helpful treatment activity selected was 'psychotherapy focusing on changing thoughts and behavior (cognitive behavioral therapy)' selected by $38.6 \%$ of respondents. With respect to medication, 'anti-depressant medication' was most frequently noted as helpful (80.3\%), and was also seen to be the most helpful medication by $73.7 \%$ respondents. Participants most frequently cited a 'psychiatrist' as being helpful (79.6\%), followed by 'psychologist' $(78.7 \%)$ and 'community mental health worker/team' (71.1\%).

\section{Factors affecting response to depression with suicidal thoughts vignette questions}

On examining the relationship between the participant's characteristics and answers to vignettes questions, it was revealed that participants who chose the correct treatment, namely 'anti-depressant medication' were younger ( $\mathrm{p}=0.023$ ) but had less nursing experience than other participants $(p=0.0047)$. Interestingly, those with higher K10 scores frequently selected 'vitamins and minerals' as a helpful medication for depression $(\mathrm{p}=0.011)$.

\section{Psychosis clinical vignette 'Saed' Problem recognition}

In response to the question 'What would you say is Saed's main problem?' 32 respondents (38.6\%) chose 'psychosis', and a further 21 (25.3\%) chose 'depression'. An additional 19 respondents $(22.9 \%)$ thought the character was suffering from 'anxiety' and collectively, these three responses accounted for $86.7 \%$ of all responses.

\section{Treatment preferences}

Table 4 shows the percentage of respondents who considered interventions within each subcategory (treatment activities, medicines or people) as 'helpful', 'harmful' or 'neither' for the problem described and which intervention they considered would be the 'most helpful.' 'Psychotherapy focusing on changing thoughts and behavior (cognitive behavioral therapy)' was the treatment activity most often considered helpful (82.3\%) followed by 'getting information about the problem and available services' (78.8\%) and 'psychotherapy focusing on causes that stem from the past' (73.4\%) The single most helpful treatment activity selected was 'psychotherapy focusing on changing thoughts and behavior (cognitive behavioral therapy)' selected by $41.4 \%$ of respondents. 'Anti-psychotic medication' was the medication most commonly noted as helpful (41.9\%). Participants most frequently cited a 'psychiatrist' as being helpful (77.8\%) followed by 'psychologist' (74.1\%) and 'community mental health worker/team' (60.8\%). 


\section{Factors affecting response to psychosis vignette questions}

There were no significant associations between problem identification, and treatment preferences and participants characteristics.

\section{Discussion}

Ascertaining the knowledge and beliefs of school nurses regarding mental illness is integral to the development of targeted educational and mental health promotion initiatives. This is the first study that has systematically sought to examine mental health literacy in school nurses in the UAE. The findings reported focus on two aspects considered to be central to mental health literacy, knowledge of mental health disorders (ability to recognize a disorder) and beliefs about the helpfulness of treatments. Although the scenarios provided align with DSM-V, the diagnostic framework employed by mental health services in the UAE, the results revealed that a significant number of respondents (the main providers of health care for school aged children and adolescents in the UAE) had difficulty identifying specific disorders accurately (49.35\% correctly identifying 'depression with suicidal thoughts' to $38.6 \%$ recognition of 'psychosis'). At best only half of the respondents surveyed were able to identify a potentially lethal mental health disorder (depression with suicidal thoughts). This limited ability to recognize a mental health disorder may well result in a delay in timely access to much needed treatment. Similar research studies report that mental health professionals surveyed in Switzerland were largely able to recognize schizophrenia and depression [34], while pharmacists surveyed in Australia exhibited high levels of mental health literacy [35].

Beliefs regarding treatment for the specific mental disorders likewise differed from the recommended clinical practice guidelines as used by psychiatry in the UAE. Treatment preferences varied according to the vignette being presented. For example, when asked about the most helpful treatment activity to assist "Miriam" (PTSD vignette) $85.2 \%$ of the respondents thought that 'Reading the Koran or Bible', would be helpful and $84.4 \%$ selected 'Getting information about the problem and available services' as the most helpful activity for Abdul's problem (depression with suicidal thoughts). For Saed's problem (psychosis) 82.3\% of respondents selected 'Psychotherapy focusing on changing thoughts and behaviors' (cognitive behavior therapy) as the most helpful treatment activity. These responses are in sharp contrast to the recommendations found in the clinical practice guidelines that inform psychiatric care in the UAE $[7,10,19]$.

In contrast, respondent's selection of preferred medications tended to reflect the recommended treatment practices. For example, almost half of the respondents identified an 'antidepressant' as the most helpful medication for Abdul's problem (depression with suicidal thoughts) and $38.6 \%$ of respondents noted that an antipsychotic would be helpful for the psychosis vignette. However, a concerning 39.1\% thought that 'Medication to help you relax' (e.g. xanax, valium) would be helpful for Miriam's problem of PTSD. Research evidence has demonstrated that the use of benzodiazepines in the treatment of PTSD is problematic and should be avoided as they can lead to significantly worsened outcomes [25].

When asked about appropriate treatment providers, mental health professionals were most frequently selected for all clinical vignettes with psychiatrist preferred by 79.6 and $77.8 \%$ for the depression with suicidal thoughts and psychosis vignettes respectively. Interestingly, psychologists were the treatment providers most frequently selected by respondents as being helpful at $83 \%$ for the PTSD vignette. These same respondents also choose 'reading religious texts' and the use of benzodiazepines as helpful in the treatment of PTSD.

Reflection on the outcome of correlations between the K10 scores and other variables (such as being able to select the right diagnosis) is an important aspect of this study. The most consistently noted factor influencing responses selected that can be considered indicative of lower mental health literacy was the level of psychological distress as reflected in the K10 score. For example, those with lower K10 scores tended to correctly identify Miriam problem as PTSD and were more likely to prefer psychologist and antidepressants as helpful treatment choices for the same vignette. With regards to Abdul's problem (depression with suicidal thoughts) those with higher K10 scores (indicative of higher levels of psychological distress) were more likely to select "Vitamins and Minerals" as a helpful medication, however those who were younger and had less clinical experience were more likely to selected an antidepressant as being helpful for Abdul. While it is acknowledged, that the findings from this cross-sectional use of the $\mathrm{K}-10$ cannot be interpreted as unequivocal, the implications do require careful consideration. Findings suggest that respondents with higher levels of personal psychological distress selected responses that may delay recognition and appropriate treatment for people experiencing mental illnesses. In some vignettes (e.g. PTSD) the age of respondents (e.g. younger participants) with low psychological stress $(\mathrm{K} 10<22)$ themselves were more sensitive to mental health problems and the associated stress than others who had higher stress levels. Respondents with lower scores on the $\mathrm{K}-10(\mathrm{~K} 10<22)$ reported less symptoms of mental health problems compared with others with high stress.

The demographic profile of respondents reveals that a considerable number of the respondents originate from 
conflict ridden countries in the Middle East or North Africa or are separated from their families and beloved ones (Indian sub-continent, Philippines). Each of these will likely have left their home country looking for a better life and safety. Given that relocation and separation from home, culture and family are identified risk factors for increased levels of psychological distress, it could be argued that a potential impact of the elevated levels of psychological distress in these respondents may be a reduced capacity to detect the signs and symptoms of mental health problems among the children, adolescents and families with whom they interact $[24,26]$.

Noteworthy was the impact of cultural and religious influences on respondents' choices on treatments deemed most helpful, for example, for PTSD reading of religious texts was identified as the most helpful activity. This finding is consistent with previous research identifying the impact of religious and cultural influences on both healthcare professionals' identification and management of mental health problems and on community members' presentation of their illnesses and health seeking behaviors as reported in the national UAE literature [2], and international literature $[6,11$, $13-15,37,44]$.

Research designed to assess the attitudes of Arab Muslim female students in the UAE, Jordan and Israel towards mental health treatment and help seeking, reported that preferences varied from seeking help from professional treatment providers in times of need to using prayers and religious practices to manage their psychological distress [2]. More recently, Slewa-Younan et al. [40] drew attention to the pluralistic nature of treatment preferences amongst people from non-Western countries and Islamic cultural contexts. While, cultural and religious activities have been described as an integral component of appropriate mental health care [38], of concern is the difficulty the respondents in this study displayed in recognizing mental illness and identifying evidence-based treatments. For school nurses working with children and adolescents and the even more vulnerable subset of this group, i.e. those with chronic conditions, an ability to respond effectively to both promote mental health and to recognize developing mental illness is essential. The importance of the school nurse role in addressing both physical and mental health needs of students is well documented [5, 20, $27,41]$.

\section{Implications}

These findings have implications for mental health promotion and education in the UAE and other countries within the GCC. Low levels of mental health literacy amongst these respondents in combination with religious and cultural factors highlight the need for curriculum enhancements for future health professionals and a targeted program of culturally appropriate professional development focused on mental health promotion for those in clinical practice. The levels of psychological distress noted in this cohort also signals a need to ensure that appropriate supports are available for clinical staff employed in schools, regular clinical supervision is encouraged and peer support is in place to promote early and appropriate help seeking. Possible screening of clinicians in conjunction with ready access to programs designed to support mental well-being will also serve to develop and support the clinical workforce caring for children and adolescents in the school setting.

\section{Limitations}

Limitations include the length of the survey. Each person was presented with the three scenarios, however, the time required to complete the full three surveys limited the number of completed surveys received. While healthcare professionals are generally fluent in English varying levels of English literacy amongst respondents may have influenced responses and limited funding and a small research team precluded the administration of the surveys by bilingual researchers. As this is the first study evaluating mental health literacy to date published in this region, no comparative data was available. Finally, the scenarios used in the survey while culturally adapted are adult-based rather than child or adolescent focused. Nevertheless, the low levels of mental health literacy identified in this sample are of concern given that respondents had completed tertiary level studies in their profession and could thus reasonably be expected to be able to recognize the three conditions covered in the survey and to identify evidence-based treatments.

\section{Conclusion}

The focus of the healthcare system in the UAE has been directed towards improving physical health with beneficial impact, and yet much remains to be done in improving health literacy in general and mental health literacy in particular. Improved mental health literacy has the potential to increase early intervention, improve promotion of mental well-being and enable effective support of the community. This study focused on mental health literacy in health professionals providing care for children and adolescents (a vulnerable section of the community whose developmental needs and in some cases chronic illnesses predispose them to mental health problems), The low levels of mental health literacy in the school nursing healthcare workforce demonstrated in this study requires urgent attention. 


\section{Authors' contributions}

NA, RR study conception/design; data analysis; drafting of manuscript; supervision; statistical expertise. WR, SY data analysis, critical revisions for important intellectual content. All authors read and approved the final manuscript.

\section{Author details}

${ }^{1}$ College of Health Sciences, University of Sharjah, Sharjah, United Arab Emirates. ${ }^{2}$ Research Institute for Medical and Health Sciences (RIMHS), University of Sharjah, Sharjah, United Arab Emirates. ${ }^{3}$ School of Nursing, Midwifery and Indigenous Health, Charles Sturt University, Orange, Australia. ${ }^{4}$ Griffith University, Brisbane, Australia. ${ }^{5}$ Mental Health, School of Medicine, Translational Health Research Institute, Western Sydney University, Sydney, Australia. ${ }^{6}$ Centre for Mental Health, Melbourne School of Population and Global Health, University of Melbourne, Melbourne, Australia.

\section{Acknowledgements}

Not applicable.

\section{Competing interests}

The authors declare that they have no competing interests.

\section{Availability of data and materials}

The datasets used and/or analysed during the current study are available from the corresponding author on reasonable request.

\section{Consent for publication}

Not applicable.

\section{Ethics approval and consent to participate}

Ethics approval was obtained from Dubai Scientific Research Ethics Committee, (Ref\#: DSREC-12/2015_13), Ministry of Health Research Ethics Committee (Ref\#: R04), and University of Sharjah Research Ethics Committee (Ref\#: $E R C / 23 / 11 / 15 / 46)$. Return of the questionnaire was considered consent to participate in the study.

\section{Funding}

This study was funded by Al-Jalila foundation—Dubai_-United Arab Emirates.

\section{Publisher's Note}

Springer Nature remains neutral with regard to jurisdictional claims in published maps and institutional affiliations.

Received: 4 October 2017 Accepted: 15 January 2018

Published online: 22 January 2018

\section{References}

1. Abuqamar M, Coomans D, Louckx F. Correlation between socioeconomic differences and infant mortality in the Arab World (1990-2009). Int J Sociol Anthropol. 2011;3(1):15-21.

2. Al-Krenawi A, Graham JR, Dean YZ, Eltaiba N. Cross-national study of attitudes towards seeking professional help: Jordan, United Arab Emirates (UAE) and Arabs in Israel. Int J Soc Psychiatry. 2004;50(2):102-14. https:// doi.org/10.1177/0020764004040957.

3. Al-Yateem N, Docherty C, Brenner M, Alhosany J, Altawil H, Al-Tamimi M. Research priorities for school nursing in the United Arab Emirates (UAE). J Sch Nurs. 2016. https://doi.org/10.1177/1059840516671783.

4. Al-Yateem N, Docherty C, Rossiter R. Determinants of quality of care for adolescents and young adults with chronic illnesses: a mixed methods study. J Pediatr Nurs. 2016;31(3):255-66. https://doi.org/10.1016/j. pedn.2015.12.003

5. Allison VL, Nativio DG, Mitchell AM, Ren D, Yuhasz J. Identifying symptoms of depression and anxiety in students in the school setting. J Sch Nurs. 2014;30(3):165-72. https://doi.org/10.1177/1059840513500076.

6. Almazeedi $\mathrm{H}$, Alsuwaidan MT. Integrating Kuwait's mental health system to end stigma: a call to action. J Ment Health. 2014;23(1):1-3. https://doi. org/10.3109/09638237.2013.775407.
7. American Psychiatric Association. Practice guideline for the treatment of patients with major depressive disorder. 3rd ed. Arlington: American Psychiatric Association; 2010.

8. Andrews G, Slade T. Interpreting scores on the Kessler Psychological Distress Scale (K10). Aust NZ J Public Health. 2001;25(6):494-7.

9. Bell MF, Bayliss DM, Glauert R, Harrison A, Ohan JL. Chronic illness and developmental vulnerability at school entry. Pediatrics. 2016;137(5):1-9. https://doi.org/10.1542/peds.2015-2475.

10. Benedek DM, Friedman MJ, Zatzick D, Ursano RJ. Guideline watch (March 2009) practice guideline for the treatment of patients with acute stress disorder and posttraumatic stress disorder; 2009. Arlington: American Psychiatric Association; 2009.

11. Bilican Fl. Help-seeking attitudes and behaviors regarding mental health among Turkish college students. Int J Mental Health. 2013;42(2):43-59. https://doi.org/10.2753/imh0020-7411420203.

12. Blackman JA, Gurka MJ, Gurka KK, Oliver MN. Emotional, developmental and behavioral co-morbidities of children with chronic health conditions. J Paediatr Child Health. 2011:47(10):742-7. https://doi. org/10.1111/j.1440-1754.2011.02044.x

13. Briggs HE. Note from the Editor: what do we really know about the role and impact of culture as a social determinant of mental health? Best Practi Mental Health. 2014:10(2):96-9.

14. Campbell RD, Long LA. Culture as a social determinant of mental and behavioral health: a look at culturally shaped beliefs and their impact on help-seeking behaviors and service use patterns of Black Americans with depression. Best Pract Mental Health. 2014;10(2):48-62.

15. Corrigan PW, Druss BG, Perlick DA. The impact of mental illness stigma on seeking and participating in mental health care. Psychol Sci Public Interest. 2014;15(2):37-70. https://doi.org/10.1177/1529100614531398.

16. Dahdouh A, Taleb M, Blecha L, Benyamina A. Genetics and psychotic disorders: a fresh look at consanguinity. Eur J Med Genet. 2016:59(2):104-10. https://doi.org/10.1016/j.ejmg.2015.12.010.

17. Delaney L, Smith JP. Childhood health: trends and consequences over the life course. Future Child. 2012;22(1):43-63.

18. Denic S, Aden B, Nagelkerke N, Essa AA. B-Thalassemia in Abu Dhabi: consanguinity and tribal stratification are major factors explaining the high prevalence of the disease. Hemoglobin. 2013;37(4):351-8. https:// doi.org/10.3109/03630269.2013.790827.

19. Dixon L, Perkins D, Calmes C. Guideline watch (September 2009) practice guideline for the treatment of patients with schizophrenia. Arlington: American Psychiatric Association; 2009.

20. Drake KL, Stewart CE, Muggeo MA, Ginsburg GS. Enhancing the capacity of school nurses to reduce excessive anxiety in children: development of the CALM intervention. J Child Adolesc Psychiatr Nurs. 2015;28(3):121-30. https://doi.org/10.1111/jcap.12115.

21. Furnham A, Hamid A. Mental health literacy in non-western countries: a review of the recent literature. Mental Health Rev J. 2014;19(2):84-98. https://doi.org/10.1108/MHRJ-01-2013-0004.

22. Ghaffar A. Summary of the national priority health research workshop. United Arab Emirates; 2010.

23. Giandinoto JA, Edward KL. The experience of mental health literacy in health professionals in non-mental health areas. Int J Health Wellness Soc 2016:6(2):1-12.

24. Gountas S, Gountas J, Soutar G, Mavondo F. Delivering good service: personal resources, job satisfaction and nurses"customer' (patient) orientation. J Adv Nurs. 2014;70(7):1553-63. https://doi.org/10.1111/jan.12308.

25. Guina J, Rossetter SR, DeRhodes BJ, Nahhas RW, Welton RS. Benzodiazepines for PTSD: a systematic review and meta-analysis. J Psychiatr Pract. 2015;21(4):281-303. https://doi.org/10.1097/PRA.0000000000000091.

26. Handley TE, Kelly BJ, Lewin TJ, Coleman C, Stain HJ, Weaver N, Inder KJ. Long-term effects of lifetime trauma exposure in a rural community sample. BMC Public Health. 2015;15:1176. https://doi.org/10.1186/ s12889-015-2490-y.

27. Health Authority of Abu Dhabi. Registered School Nurses Scope of Practice. Abu Dhabi, UAE; 2015. http://schoolsforhealth.haad.ae/ media/29304/registered_school_nurse.pdf. Accessed 3 Jan 2017.

28. Jorm AF, Korten A, Jacomb P, Christensen H, Rodgers B, Pollitt P. "Mental health literacy": a survey of the public's ability to recognise mental disorders and their beliefs about the effectiveness of treatment. Med J Aust. 1997:166(4):182-6. 
29. Kapungwe A, Cooper S, Mayeya J, Mwanza J, Mwape L, Sikwese A, Lund C. Attitudes of primary health care providers towards people with mental illness: evidence from two districts in Zambia. Afr J Psychiatry (Johannesburg). 2011;14(4):290-7. https://doi.org/10.4314/ajpsy.v14i4.6.

30. Kessler RC, Andrews G, Colpe LJ, Hiripi E, Mroczek DK, Normand SLT, Zaslavsky AM. Short screening scales to monitor population prevalences and trends in non-specific psychological distress. Psychol Med. 2002. https://doi.org/10.1017/s0033291702006074.

31. Koutelekos J, Haliasos N. Depression and thalassemia in children, adolescents and adults. Health Sci J. 2013;7(4):239-46.

32. Mohammed bin Rashid Al Maktoum. Vision 2021 united in ambition and determination. http://www.vision2021.ae. (2015) Accessed 3 Jan 2017.

33. Ndetei DM, Khasakhala LI, Mutiso V, Mbwayo AW. Knowledge, attitude and practice (KAP) of mental illness among staff in general medical facilities in Kenya: practice and policy implications. Afr J Psychiatry (Johannesbg). 2011;14(3):225-35. https://doi.org/10.4314/ajpsy.v14i3.6.

34. Nordt C, Rössler W, Lauber C. Attitudes of mental health professionals toward people with schizophrenia and major depression. Schizophr Bull. 2006;32(4):709-14. https://doi.org/10.1093/schbul/sbj065.

35. O'Reilly CL, Bell JS, Chen TF. Pharmacists' beliefs about treatments and outcomes of mental disorders: a mental health literacy survey. Aust NZ J Psychiatry. 2010;44(12):1089-96. https://doi.org/10.3109/00048674.2010. 512864.

36. Patel V, Chisholm D, Dua T, Laxminarayan R, Medina-Mora ME, editors. Mental, neurological, and substance use disorders. 3rd ed. Washington D.C.: World Bank; 2015.

37. Patel V, Minas H, Cohen A, Prince MJ, editors. Global mental health: principles and practice. New York: Oxford University Press; 2014.
38. Rassool GH, editor. Cultural competence in caring for muslim patients. Hampshire: Palgrave Macmillan; 2014

39. Saadat M. Association between healthy life expectancy at birth and consanguineous marriages in 63 countries. J Biosoc Sci. 2011;43(4):475-80. https://doi.org/10.1017/S0021932011000034.

40. Slewa-Younan S, Mond J, Bussion E, Mohammad Y, Uribe Guajardo MG, Smith M, Jorm AF. Mental health literacy of resettled Iraqi refugees in Australia: knowledge about posttraumatic stress disorder and beliefs about helpfulness of interventions. BMC Psychiatry. 2014;14(1):1-8. https://doi. org/10.1186/s12888-014-0320-x.

41. Stevenson BA. Evolving roles for school nurses: addressing mental health and psychiatric concerns of students. NASN Sch Nurse. 2010;25(1):30-3. https://doi.org/10.1177/1942602x09353915.

42. Sulaiman-Hill CMR, Thompson SC. Selecting instruments for assessing psychological wellbeing in Afghan and Kurdish refugee groups. BMC Res Notes. 2010;3:237.

43. Supreme Council of Health Qatar. (2013). Qatar - National Mental Health Strategy. Changing minds, changing lives 2013-2018. Doha. http://nhsq. info/app/media/1166. Accessed 3 Jan 2017.

44. Weatherhead S, Daiches A. Muslim views on mental health and psychotherapy. Psychol Psychother Theory, Res Pract. 2010;83(Pt 1):75-89. https://doi.org/10.1348/147608309X467807.

45. World Health Organisation. Global status report on noncommunicable diseases. Switzerland: World Health Organisation; 2014

46. Yousef S, Eapen V, Zoubeidi T, Kosanovic M, Mabrouk AA, Adem A. Learning disorder and blood concentration of heavy metals in the United Arab Emirates. Asian J Psychiatry. 2013;6(5):394-400. https://doi.org/10.1016/j. ajp.2013.04.005.

\section{Submit your next manuscript to BioMed Central and we will help you at every step:}

- We accept pre-submission inquiries

- Our selector tool helps you to find the most relevant journal

- We provide round the clock customer support

- Convenient online submission

- Thorough peer review

- Inclusion in PubMed and all major indexing services

- Maximum visibility for your research

Submit your manuscript at www.biomedcentral.com/submit 